\title{
Enhancing Learning Outcomes Through Application Driven Activities In Marketing
}

Nicole Stegemann, University of Western Sydney, Australia Catherine Sutton-Brady, University of Sydney, Australia

\begin{abstract}
This paper introduces an activity used in class to allow students to apply previously acquired information to a hands-on task. As the authors have previously shown active learning is a way to effectively facilitate and improve students' learning outcomes. As a result to improve learning outcomes we have overtime developed a series of learning activities reinforcing marketing theories. In this paper, we provide details of a marketing communications exercise which in addition to being a vehicle for active learning also allowed students to apply the results of their previous research thereby effectively aligning all learning and assessment tasks. The activity required students to take a previously completed environmental analysis of a foreign country and using that information develop a print advertisement for an Australian branded product unavailable in that country. Details are provided on the in-class activity including guidelines for conducting the practice-orientated exercise and information on the assessment tasks leading up to this activity. The paper provides academics with an example of how to apply concepts to real life examples in the classroom and give students hands on experience and further shows how learning can be scaffolded through assessment. We found that students actively engaged in the experience and improved their learning outcomes through application of their previous research and the concepts discussed in class.
\end{abstract}

Keywords: Active Leaning; Application Driven and Marketing Education

\section{INTRODUCTION}

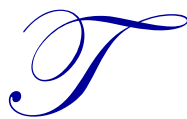

he activity reported in this paper was implemented at an Australian university in the subject International Marketing (at postgraduate level). This subject is an elective subject for the students concerned. The subject focuses on the dynamic nature of international marketing. One of its aims is to give students a critical appreciation of the inherent challenges contemporary firms encounter in creating and maintaining competitiveness globally. The subject is undertaken in one semester (10 weeks), which consists of 40 contact hours in class. Within this subject a combination of different activities are used however this paper deals specifically with the marketing communications activity.

Our rationale for using this marketing communications activity is presented in the first section, where we provide the findings of an investigation into the existing literature on the use of hands-on and application based activities. Based on the literature review we set the objectives for the exercise and look at the way in which we aimed to achieve these objectives. We provide a brief explanation of the strategic importance of marketing communications in international marketing to highlight the relevance of this exercise. We describe in detail how the activity was implemented which allows for others to replicate this in their courses.

\section{APPLIED ACTIVE LEARNING}

Our previous research in this area has led us to firmly believe that the biggest challenge in business education is finding ways of bringing reality to the class room to keep students engaged. We are not the only ones to recognize this as crucial and other researchers have long recognized the importance of bringing relevance and real life experience to the classroom (Sutton-Brady 2006; Elam and Spotts 2004; Kennedy, Lawton and Walker 2001; 
Razzouk, Seitz and Rizkallah 2003; Tabor 2005; Young 2002; Zych 1997). Hands-on experience is also seen as a vital part of students' learning experience (Granitz 2001). Many business schools around the world have realized as well that this is important and have integrated industry placements into their courses. But this is not always possible for all schools and therefore finding ways of making classroom learning more active and realistic allows students to experience applying theory and knowledge to real life problems.

Traditionally university teaching and learning was very passive but action learning moves away from that by instigating learning through experience, where the environment is the classroom and the task the vehicle for learning (Smith and O'Neill 2003). This move has in part come about because of the criticism of traditional teaching approaches at universities as noted by Cunningham 1991 (cited in Jones-Evans et al 2000) "if one accepts that high professional performance is a function of the successful combination of knowledge, skills and attitudes, then typically business schools have focused on the first, largely ignored the second and assumed the third".

This argument has been furthered by many authors who show that students have expressed a strong interest in applying their classroom knowledge and many authors have shown how active learning can achieve this (McConnell et al 2003; Hamer 2000; Gremler et al 2000) It is strongly felt by Gremler et al (2000) that 'students must experience the class material and make it part of themselves' and that this does not occur 'when students simply listen to lectures, memorize information and take objective exams'.

Active learning has been described as a broad concept, which involves a number of instructional techniques (Bicknell-Holmes \& Hoffmann 2000). This is an important definition for us as we utilize active learning in a number of ways and for this particular activity are using it in a very applied manner. Not much has been written about the application approach as in many cases it is assumed. But for us it is vital as we have the students engage with their research and build on that assessment thereby scaffolding their learning.

\section{SPECIFIC LEARNING OBJECTIVES}

As with previous activities we designed and implemented (Sutton-Brady and Stegemann 2010, Stegemann and Sutton-Brady 2011), we wanted to design an activity that would be directly aligned with learning outcomes of our unit International Marketing at postgraduate level. Application driven activities provide students with real life examples and can be tied in with learning outcomes as well as subject content. This activity's learning outcomes include:

- Design an application driven activity that gets students involved and let them apply theoretical concepts and findings from their first assignment (Marketing Environment Analysis for a foreign country of their choice).

- $\quad$ Provide an engaging environment that also fosters teamwork.

- $\quad$ Create an activity that uses real-life marketing cases and relates to students' interests and experiences. (It is easier to get students involved and increase their own knowledge when using activities they are familiar with (Pearce \& Sutton-Brady 2003). Dacko (2001) also highlighted that students' learning is increased when context is situation driven as well as when students can see, listen, and read about it.

- Increase critical thinking.

- Increase learning outcomes through increasing students' level of motivation and engagement.

\section{APPLICATION DRIVEN ACTIVITY}

As demonstrated above, research studies support that students show increased engagement and interest when completing application driven class activities. As for our other activities, our objective was to tap into students' areas of interest, increase their engagement and importantly encourage critical thinking. We have designed four marketing mix strategy activities asking students to apply the knowledge they gained through the marketing environment analysis, which they had to complete throughout the first part of the subject. In this paper, we now present our marketing communications activity; our other activities will be presented in future papers. 
Students formed groups in week 1 and jointly decided on the country and brand to be analysed. Students usually choose a country and brand they have some familiarity with and definitely interested in. Often at least one student has firsthand experience and knowledge about the foreign country. They then complete the marketing environment analysis. The environmental analysis forms the first assignment due in the middle of the class schedule, and has been discussed and graded by the time the marketing mix activities take place. They have therefore at this stage had considerable feedback on how to improve it. Our marketing communications activity asks students to reflect on their marketing environment analysis and based on their findings to develop a print advertising campaign that can include print ads, leaflets, posters, etc.

Marketing communications strategies form a crucial element to communicate a company's brand identity and image with the overall objective to increase brand equity. Marketing communications facilitates the formation of strong, unique and favourable associations. Advertising in particular aids to inform, persuade and remind customers of a brand and its attributes.

Students usually enjoy the marketing communications topic and are naturally motivated and interested in it. They also believe that they know everything about it, as they are exposed to it non-stop. This activity is great to demonstrate the complexity and challenges that come with the design of a marketing communications strategy, here in particular, a print advertising campaign.

Students are advised to bring a copy of their marketing environment analysis to each class covering the marketing mix elements. In the beginning of the class, students are asked to draw a diagram that depicts the marketing communications process and elements (e.g. Sender, Message, Media, Receiver, Noise, and Response) including the influencing variables (availability, cost, legal constraints, etc.). Once they have completed their diagrams, they hang them on the wall for comparison and discussion. This activity takes about 30 minutes including discussion and ensures that all students understand the theory and use the same frameworks.

Following the warm-up activity, students are then instructed to design a print campaign (e.g. poster, magazine/newspaper ad, leaflet, etc.) for their chosen product and country based on their environmental analysis. They are given A1 sheets and markers and have 45 to 60 minutes to discuss and develop their strategy, the design and layout including visualisation. Once completed, students hang up their print strategies and present them in turn. Each group has to explain and justify their strategy and convince the class that it will reach the target audience. We encourage students to critically analyse each others' strategies and to ask questions, which fosters lively discussions.

We also ask the students to write down the information they would have needed for the design of the strategy, but did not include in their marketing environment analysis. Naturally, students have gaps in their environment analysis, as they don't have the experience yet to consider all marketing mix decisions when putting it together. Their cultural awareness is heightened with this activity as they realise the importance of getting their message across in a foreign country.

Below are two examples of student work. The first advertisement promotes UGG boots in China focusing on young fashion-conscious women. The advertisement combines Australian fashion and quality with Chinese symbols such as the colour red. The second advertisement emphasises the health benefits of homogenised milk. It further suggests that it provides strength and energy, which appeals to the male market. 


\section{UGG Boots To China}

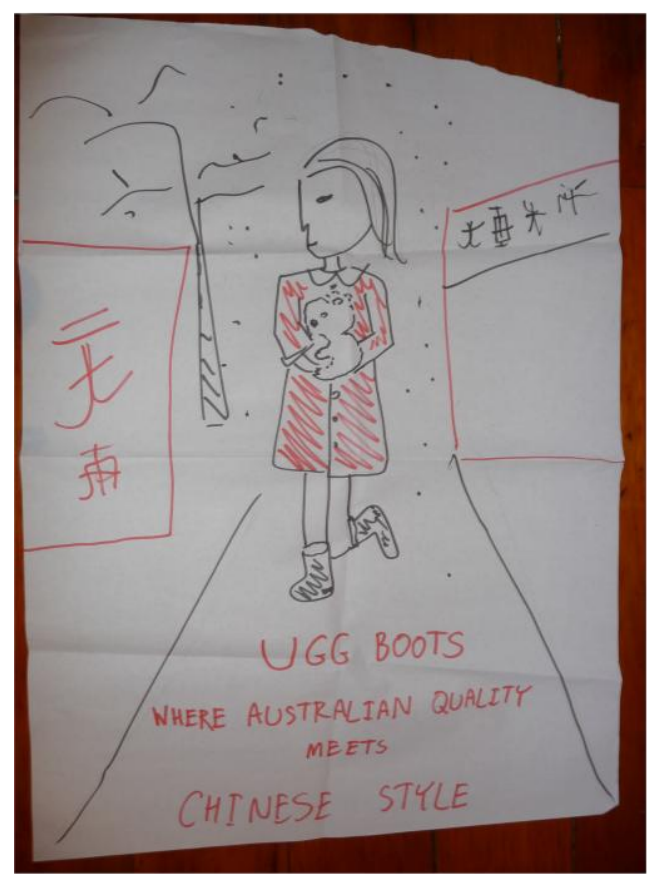

Dairy Farmers to India

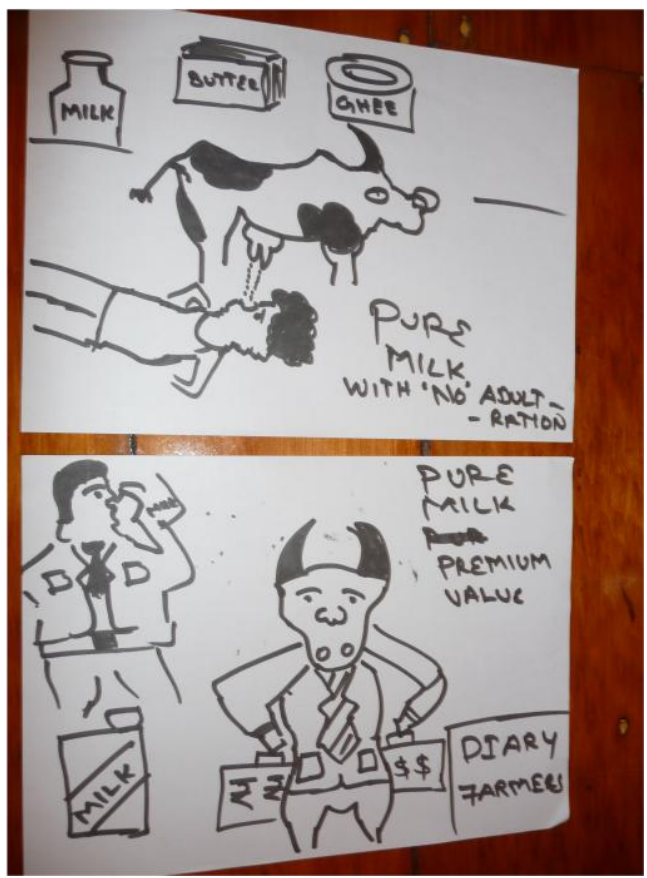

\section{CONCLUSION}

Our aim in designing and implementing this activity was to create an interactive learning activity that is current and relevant and also can be easily implemented by other educators. We feel this paper has definitely allowed us to achieve this aim. It has also been encouraging for us as educators to see the success of this activity especially in terms of student learning. This success encourages us to continue with the development of interactive class activities and to increase the variety of teaching methods used in class. In particular the applied nature of the activity really added value to the student experience. Students felt also that they could now see the relevance of previous assessment tasks and were appreciative of the scaffolded nature of the approach.

Providing students with an avenue for using their previous research is a highlight of this approach. They can clearly see how what they have learned can be applied. Most importantly many become very conscious of what they have missed in their previous assessment and it makes them realize that so much more can be done. This pushes them to make improvements to their original analysis thereby clearly increasing their learning outcomes.

\section{AUTHOR INFORMATION}

Associate Professor Catherine Sutton-Brady is Associate Professor of Marketing at The University of Sydney Business School. She holds a PhD in marketing from the University of Western Sydney. Since her return to academia in the early 90s her teaching has focused on international marketing and business to business marketing. Her research interests also lie in the area of business to business marketing and international marketing. She has published in these areas as well as in the area of higher education and assessment. Catherine is a member of the Editorial Board for Industrial Marketing Management. Catherine has won numerous awards for outstanding teaching, most recently being awarded the ANZMAC Pearson, Distinguished Marketing Educator Award. E-mail: c.sutton-brady@econ.usyd.edu.au (Corresponding author)

Nicole Stegemann has been a Lecturer in the School of Business at University of Western Sydney for 12 years. Concurrently, Nicole has been consulting in brand strategy management and marketing for a diverse range of 
industries. Nicole holds a PhD in Marketing from UTS. Her research interests are in the area of consumer behaviour, especially luxury brand management, and teaching and learning. Nicole has published in international economics, marketing and education journals. Nicole is a member of the editorial board for the Journal for Advancement of Marketing. E-mail: n.stegemann@uws.edu.au (Corresponding author)

\section{REFERENCES}

1. Bicknell-Holmes, T. and Hoffman, P.S. (2000) "Elicit, engage, experience, explore: discovery learning in library instruction" Reference Services Review.

2. Dacko, S.G. (2001) "Narrowing skill development gaps in marketing and MBA programs: The role of innovative technologies for distance learning," Journal of Marketing Education, Vol. 23, No. 3, p.228-239.

3. Duncan, T. and Moriarity, S. (1998) "A communication-based marketing model for managing relationships," Journal of Marketing, Vol. 62, p.1-13.

4. Elam, E.L.R. and Spotts, H.E. (2004) "Achieving marketing curriculum integration: A live case study approach," Journal of Marketing Education, Vol. 26, No. 1 p.50-65.

5. $\quad$ Gremler, D.D., Hoffman, K.D., Keaveney, S.M. and Wright, L.K. (2000) "Experiential Learning Exercises in Services Marketing Courses," Journal of Marketing Education, Vol. 22, No. 1 p.35-44.

6. Granitz, N. A. (2001) "Active Learning and morality: incorporating greater meaning into marketing education," Marketing Education Review, Vol. 11, No. 2.

7. Hamer, L.O. (2000) "The Additive Effects of Semistructured Classroom Activities on Student Learning: An Application of Classroom-Based Experiential Learning Techniques," Journal of Marketing Education, Vol. 22, No. 1, p.25-34. Vol. 28, Iss: 4, pp.313-322.

8. Hormby, T. (2006) "The Story behind the Sony Walkman," http://lowendmac.com/orchard/06/sonywalkman-origin.html, accessed on 22 May 2011.

9. Jones-Evans, D., Williams, W. and Deacon, J. (2000) "Developing entrepreneurial graduates: an actionlearning approach" Education + Training, Vol. 42 Iss 4, pp.282-288.

10. Kennedy, E.J., Lawton, L. and Walker, E. (2001) "The case for using live cases: Shifting the paradigm in marketing Education" Journal of Marketing Education, Vol. 23, No. 2, p.145-151.

11. McConnell, D.A., Steer, D.N. and Owens, K.D. (2003 "Assessment and Active Learning Strategies for Introductory geology Courses," Journal of Geoscience Education, Vol. 51, No. 2, p.205-216.

12. Pearce, G. \& Sutton-Brady, C. (2003) "International Business Theatre (IBT): An alternative assessment method for enhancing student learning in International Marketing," Assessment \& Evaluation in Higher Education, Vol. 28, No.1, pp.3-15.

13. Razzouk, N.Y., Seitz, V. and Rizkallah, E. (2003) "Learning by doing: Using experiential projects in the undergraduate marketing strategy course," Marketing Education Review, Vol. 13 No. 2.

14. Smith, P.A.C. and O’Neil, J. (2003) “A review of action learning literature 1994-2000: Part 1 bibliography and comments" Journal of Workplace Learning, Vol.15, No. 9 pp.63-69.

15. Smith, L.W. and Van Doren, D.C. (2004) "The reality-based learning method: A simple method for keeping teaching activities relevant and effective," Journal of Marketing Education, Vol. 26, No. 1 p. 6674.

16. Stegemann N. and Sutton-Brady C. (2011) "Branding in the Classroom", Proceedings of the European College Teaching \& Learning ECTL Conference 2011, Barcelona, Spain, June 2011

17. Sutton-Brady C. and Stegemann N. (2010) “Assessing Methods to Improve Class Participation”, Proceedings of the European College Teaching \& Learning ECTL Conference 2010, Dublin, Ireland, June 2010

18. Sutton-Brady, C. (2006) "Innovation in Assessment: Injecting Reality into Business Education," Journal of College Teaching and Learning, Vol.3, No.10.

19. Tabor, S.W. (2005) "Achieving significant learning in E-Commerce education through small business consulting projects," Journal of Information Systems Education, Vol.16, No. 1.

20. Young, M.R. (2002) "Experiential Learning=Hands-On+Mind-On” Marketing Education Review, Vol. 12 No. 1.

21. Zych, J.M. (1997) “Adding case materials to reinforce the realism in marketing simulations," Marketing Education Review, Vol. 7, No. 2. 
NOTES 